\title{
Ambulatory anesthesia: optimal perioperative management of the diabetic patient
}

This article was published in the following Dove Press journal:

Ambulatory Anesthesia

10 May 2016

Number of times this article has been viewed

\section{Jorinde AW Polderman \\ Robert van Wilpe \\ Jan $\mathrm{H}$ Eshuis \\ Benedikt Preckel \\ Jeroen Hermanides}

Department of Anaesthesiology, Academic Medical Centre, University of Amsterdam, Amsterdam, the Netherlands
Correspondence: Jorinde AW Polderman Department of Anaesthesiology, Academic Medical Centre, University of Amsterdam, PO Box 22660, I I00DD Amsterdam, the Netherlands

$\mathrm{Tel}+3 \mathrm{I} 205669 \mathrm{III}$

Fax +3। 20697944 ।

Email j.a.polderman@amc.uva.nl

\begin{abstract}
Given the growing number of patients with diabetes mellitus (DM) and the growing number of surgical procedures performed in an ambulatory setting, DM is one of the most encountered comorbidities in patients undergoing ambulatory surgery. Perioperative management of ambulatory patients with DM requires a different approach than patients undergoing major surgery, as procedures are shorter and the stress response caused by surgery is minimal. However, DM is a risk factor for postoperative complications in ambulatory surgery, so should be managed carefully. Given the limited time ambulatory patients spend in the hospital, improvement in management has to be gained from the preanesthetic assessment. The purpose of this review is to summarize current literature regarding the anesthesiologic management of patients with DM in the ambulatory setting. We will discuss the risks of perioperative hyperglycemia together with the pre-, intra-, and postoperative considerations for these patients when encountered in an ambulatory setting. Furthermore, we provide recommendations for the optimal perioperative management of the diabetic patient undergoing ambulatory surgery.
\end{abstract}

Keywords: diabetes mellitus, perioperative period, ambulatory surgery, insulin, complications, GLP-1 agonist, DPP-4 inhibitor

\section{Introduction}

Diabetes mellitus (DM) is a growing concern worldwide. The current global prevalence of DM was estimated to be $9 \%$ among adults aged 18 years or older. ${ }^{1}$ According to current projections, the prevalence will rise from 387 million people now to 592 million people in 2035 worldwide. $^{2}$ Patients with DM are more prone to undergo surgical interventions; $\sim 25 \%$ of patients with DM will require surgery. ${ }^{3}$ Given the increasing number of surgical procedures being performed on an outpatient basis, ${ }^{4} \mathrm{DM}$ is one of the most commonly encountered comorbidities in the ambulatory setting.

Although a vast amount of research has been done on the negative effects of hyperglycemia and DM in the perioperative period of major (cardiac) surgery, ${ }^{5-9}$ evidence regarding DM and ambulatory surgery is sparse. However, it is known that DM is an important risk factor for postoperative complications (such as wound infections or unplanned admissions) in surgical outpatients. ${ }^{10}$ The recently updated Joint British Diabetes Societies/National Health Service (JBDS/NHS) guideline states that sameday admission should be standard of care in patients with DM unless other serious comorbidities are present. ${ }^{11}$ Therefore, the preoperative assessment plays a major role in the management of DM during ambulatory surgery. Furthermore, intraoperative management of outpatients with DM might require a different approach than 
in-patients with DM taking into account the short time spent in the hospital, short duration of surgery, and minimal stress response after smaller surgical procedures. ${ }^{12,13}$ The purpose of this review is to summarize current literature regarding the anesthesiologic management of patients with DM in the ambulatory setting. We will discuss the risks of perioperative hyperglycemia together with the pre-, intra-, and postoperative considerations for these patients when encountered in an ambulatory setting.

\section{Perioperative hyperglycemia and complications}

Tissue damage caused by surgery leads to an increased production of stress hormones (eg, cortisol and catecholamines), thereby reducing insulin sensitivity and secretion. ${ }^{14}$ The resulting elevation in blood glucose levels is frequently referred to as stress hyperglycemia. Since the capacity to respond to the increased insulin demand is reduced or absent in patients with DM, the risk of developing hyperglycemia during or after surgery is higher. Perioperative hyperglycemia during major surgery has a significant impact on the occurrence of postoperative complications, including various infections, impaired wound healing, and myocardial infarction. , $^{6,15-17}$ Treating perioperative hyperglycemia has been shown to reduce postoperative infections. ${ }^{15,18}$

The underlying pathophysiologic mechanisms by which hyperglycemia leads to an increase in deleterious outcomes have not yet been fully elucidated. ${ }^{19}$ However, multiple mechanisms by which hyperglycemia might contribute to postoperative complications have been proposed. First, clinical studies suggest that hyperglycemia causes decreased monocyte and neutrophil function, reduced intracellular antibacterial activity, and glycosylation of immunoglobulins resulting in an increased risk of infections. ${ }^{20,21}$ Second, hyperglycemia activates pro-inflammatory cytokines, which will lead to a pro-inflammatory state and subsequently to an increased risk of infection and impaired wound healing. ${ }^{22}$ Third, experimental animal models showed that hyperglycemia is associated with lower cell count of endothelial progenitor cells and decreased nitric oxide bioavailability leading to decreased endothelial function and contributing to a higher risk of infections, impaired wound healing, and thrombotic complications. ${ }^{19,23}$ Finally, an increase in glucose leads to upregulation of coagulation factors, thereby promoting a pro-thrombotic state in the perioperative period. ${ }^{24,25}$ Furthermore, untreated hyperglycemia can result in severe dehydration, ketoacidosis, and hyperosmolar states. ${ }^{12}$
When blood glucose levels are persistently elevated, glucose binds to the hemoglobin in erythrocytes. ${ }^{26}$ The percentage of hemoglobin in the glycosylated form ( $\mathrm{HbA1c}$ ) reflects mean ambient fasting and postprandial glucose levels over a 3-4-month period and reveals whether the patient resides mostly in the normoglycemic or hyperglycemic range..$^{27,28}$ Research suggests that the oxygen carrying capacity of hemoglobin seems to be unaffected by the level of glycosylation. ${ }^{29,30}$ Nonetheless, several studies demonstrated the association between elevated $\mathrm{HbAlc}\left(>53 \mathrm{mmol} \mathrm{mol}^{-1}\right)$ and postoperative complications after noncardiac surgery. ${ }^{31-35}$ Furthermore, preoperative hyperglycemia and elevated $\mathrm{HbA1c}$ levels are predictive for postoperative hyperglycemia after ambulatory surgery. ${ }^{10}$ These data suggest that improvement of preoperative glucose regulation in patients with DM should be pursued and the surgical procedure even postponed both for better perioperative glycemic control and prevention of postoperative complications. ${ }^{11}$ This holds true especially for ambulatory surgery when monitoring of blood glucose is often limited. ${ }^{36}$

As stated before, hyperglycemia during major surgery is associated with adverse outcomes. ${ }^{6,15-17}$ In a prospective cohort study in ambulatory patients, DM was found to be a risk factor for postoperative complications after minor ambulatory surgery, such as postoperative infections or unplanned admissions. ${ }^{10}$ Hyperglycemia (glucose $>7.8 \mathrm{mmol} \mathrm{L}^{-1}$ ) occurred in $65 \%$ of the patients with DM during ambulatory surgery compared to only $5.6 \%$ of the patients without DM. Contrary to DM, hyperglycemia was not associated with postoperative infections, suggesting that long-term glycemic control is of greater influence than short-term glycemic control during ambulatory surgery. Unfortunately, only a limited number of patients with DM were included ( $\mathrm{n}=48,5.3 \%$ ); thus, the consequences of perioperative hyperglycemia in patients with DM during ambulatory surgery should still be investigated.

Also, postoperative hyperglycemia is associated with postoperative complications after major surgery. ${ }^{6}$ Treating postoperative hyperglycemia results in significantly less postoperative complications. ${ }^{18}$ This indicates that perioperative glucose regulation does not end when the patient leaves the recovery room or is discharged to home in the case of ambulatory surgery. Regrettably, no data exist on glycemic control of DM patients during the first days after discharge following ambulatory surgery.

\section{Preoperative considerations}

Preoperatively, the anesthesiologist should obtain information about the type and duration of diabetes, antidiabetic 
medications, treatment compliance, and diabetes-related complications. Furthermore, long-term glycemic control should be established by laboratory measurements (eg, HbA1c, creatinine). When long-term glycemic control is poor $\left(\mathrm{HbAlc}>69 \mathrm{mmol} \mathrm{mol}^{-1}\right)$, JBDS/NHS guidelines suggest to optimize glycemic control and postpone the operation, if possible. ${ }^{11}$ In addition, the incidence of hypoglycemic episodes and the blood glucose level at which symptoms occur should be known.

Deliberate management of the antidiabetic therapy is crucial in order to safely ensure adequate perioperative glycemic control. Temporary cessation of oral antidiabetic therapy and insulin therapy increases the risk of perioperative hyperglycemia. Meanwhile, fasting - especially in patients on tight glycemic control or who snack regularly - increases the risk of hypoglycemia. ${ }^{11}$ To avoid hyper- and hypoglycemia, it is important to minimize the disruption of the usual treatment regimen by scheduling DM patients first on the procedure list. ${ }^{11,12}$

To improve patient adherence to the preoperative management, explicit verbal and written instructions should be provided concerning blood glucose monitoring, therapy adjustments, and fasting times. ${ }^{37}$ Patients should be instructed to measure their glucose regularly on the day of surgery. Furthermore, they should be advised to bring sugar-containing beverages or buccal sugar cubes with them to treat hypoglycemia during transit to the surgical facility. ${ }^{13}$ Postoperative dehydration can be prevented by adequate water consumption until 2 hours before surgery. ${ }^{12}$

\section{Oral antidiabetics}

The first-line oral drug for treatment of DM 2 is metformin, which stimulates glycogen synthesis thereby reducing gluconeogenesis in the liver. It also increases peripheral insulin sensitivity in muscle cells by increasing the transport capacity of the membrane glucose transporters. As metformin does not trigger insulin production, there is virtually no risk of hypoglycemia when metformin is used as monotherapy. ${ }^{38}$ Metformin has long been associated with an increased risk of lactic acidosis, which is the reason why metformin is often withheld prior to surgery. A meta-analysis of 347 studies demonstrated that there is no evidence supporting this association, even in the presence of renal insufficiency. ${ }^{39}$ Nonetheless, we are still awaiting randomized controlled trials investigating the effects of perioperative continuation of metformin. The JBDS/NHS guidelines recommend continuation of metformin throughout the day of surgery if the fasting period is short (ie, no more than one missed meal), provided no contrast medium is used and the estimated glomerular filtration rate is greater than $50 \mathrm{~mL} / \mathrm{min} / 1.73 \mathrm{~m}^{2} .{ }^{11}$

Sulfonylureas (eg, tolbutamide, gliclazide, and glimepiride) and meglitinides (eg, repaglinide) are not safe to be taken on the day of surgery as they trigger insulin production, which could potentially lead to hypoglycemia in fasting patients. ${ }^{40}$ In addition, they interfere with cardiac ischemic preconditioning. ${ }^{41}$ Thiazolidinediones (eg, pioglitazone) are known to cause fluid retention and therefore generally discontinued several days prior to surgery. ${ }^{42}$ Alpha glucosidase inhibitors (eg, acarbose, miglitol) should be discontinued during perioperative fasting since their only mechanism of action is to impede glucose absorption after meals. ${ }^{43}$

Over the past decade, incretin-based therapies, glucagonlike peptide-1 (GLP-1) agonists, and dipeptidyl peptidase-4 (DPP-4) inhibitors, are increasingly used in the treatment of DM 2. GLP-1 is a hormone secreted by the small intestine when food is ingested. When GLP-1 binds with the GLP-1 receptor, the pancreas will start producing insulin in a glucose-dependent matter. ${ }^{44}$ GLP-1 secretion is counteracted by DPP-4, which rapidly breaks down GLP-1. Current therapeutic applications are DPP-4 inhibitors, which have been developed to slow down the GLP-1 breakdown process, thereby increasing the circulation time of GLP-1. In addition, GLP-1 agonists are a synthetic analog of GLP-1, which interact with the GLP-1 receptors. Because of a resistance to DPP-4 breakdown and increased half-life, they can be administered once daily or less. ${ }^{45}$ Incretin-based therapies as monotherapy are unlikely to cause hypoglycemia because of their glucose-dependent action. ${ }^{42}$ Perioperative use of incretin-based injectables may occasionally cause hypoglycemia but almost exclusively when combined with other antidiabetics - for instance, exenatide in combination with sulfonylureas. ${ }^{46,47}$ Some caution should be taken as GLP-1 agonists may delay restoration of gastrointestinal function after surgery as they slow gastric emptying and gut motility. DPP-4 inhibitors are usually better tolerated than GLP-1 agonists with no significant adverse effects. ${ }^{42,46}$ In rats, GLP-1 secretion was reduced during isoflurane anesthesia with restoration of normal function after treatment with a GLP-1 agonist. ${ }^{48}$ These data suggest that an incretin-based therapy in the perioperative period seems a suitable approach. The most recent JBDS/NHS guidelines suggest to continue incretin-based therapies, whereas American guidelines were more prudent and advise to withhold incretin-based therapies $12-24$ hours before surgery. ${ }^{11-13} \mathrm{Up}$ to date, especially when used as monotherapy, continuation during ambulatory surgery seems not to be contraindicated. 
Sodium-glucose cotransporter 2 (SGLT-2) inhibitors have recently been introduced as a novel oral antidiabetic agent. These agents block the reabsorption of glucose in the kidney, lowering the glucose threshold by which it is excreted in the urine. They have a low risk of hypoglycemia as the excretion of glucose ceases when blood glucose levels drop below the threshold. ${ }^{49}$ However, due to increased diuresis, plasma volume is reduced by $10 \%$ after initiation of treatment. ${ }^{50}$ Furthermore, SGLT-2 inhibitors are associated with diabetic ketoacidosis. ${ }^{51}$ Due to their noninsulin dependent glucose excretion, extreme hyperglycemia is usually absent, and nausea and vomiting are the only warning signs of diabetic ketoacidosis. ${ }^{52}$ In the postoperative setting, it will become quite hard to distinguish between diabetic ketoacidosis and postoperative nausea and vomiting (PONV), especially in the diabetic patient with a glucose level of $10 \mathrm{mmol} \mathrm{L}^{-1}$ on SGLT-2 inhibitors. Thus, when in doubt, urine or plasma ketones should be measured. Based on these data, we would suggest stopping SGLT-2 inhibitors on the day of surgery.

Overall, we suggest withholding oral antidiabetics - with the exception of metformin and incretins - 12-24 hours before surgery until oral intake is resumed (Table 1).

\section{Insulin therapy}

As insulin requirements differ between patients, numerous different insulin regimens can be encountered. The preferred insulin regimen for patients with insulin-dependent DM is a basal-bolus regimen, as it mimics the physiological insulin production by providing basal doses of long-acting insulin and prandial doses of short- or rapid-acting insulin. Long-acting insulin only, is an alternative regimen used primarily in patients with DM 2. Since long-acting insulin is used to account for insulin demand between meals, perioperative fasting should not lead to hypoglycemia if the usual dose is continued. Intermediate-acting insulin (eg, neutral protamine Hagedorn) or premixed insulin differs from the long-acting regimens, as they may cause hypoglycemia in fasting patients because of their peak effect. ${ }^{53}$

Our recommendations for the preoperative management of various insulin regimens are depicted in Table 2, where we have tried to make the recommendations as uniform as possible for better protocol adherence. ${ }^{54-56}$ It has been proposed that fasting patients require $50 \%$ of their total daily insulin dose because of their fasting state and reduced metabolic demands during anesthesia. However, due to short operating times and early resumption of oral intake, insulin requirements during ambulatory surgery are probably closer to $100 \%$ of the total daily insulin dose. Thus, in agreement with Society for Ambulatory Anesthesia (SAMBA) guidelines, patients on long-acting insulin may take their usual morning or evening dose, irrespective of the duration of fasting. ${ }^{12}$ However, the newer long-acting insulins Toujeo ${ }^{\circ}$ and Degludec have a duration of action of 36 to 42 hours compared to 24 hours for Lantus ${ }^{\mathcal{O}}$ or Detemir. Therefore,

Table I Perioperative management of oral antidiabetics

\begin{tabular}{|c|c|c|c|}
\hline Drug class & Primary mechanism of action & Main perioperative risks & Recommendation \\
\hline $\begin{array}{l}\text { Biguanides } \\
\text { (metformin) }\end{array}$ & $\begin{array}{l}\text { Reduces hepatic gluconeogenesis, } \\
\text { increases insulin sensitivity }(T 1 / 2: 6-18 \mathrm{~h})\end{array}$ & None* & $\begin{array}{l}\text { Continue. May be withheld in } \\
\text { case of renal failure or when } \\
\text { using contrast agents }\end{array}$ \\
\hline $\begin{array}{l}\text { Sulfonylureas } \\
\text { (tolbutamide, gliclazide, } \\
\text { glimepiride) }\end{array}$ & Stimulates insulin release $\left(T^{1} / 2: 2-10 \mathrm{~h}\right)$ & $\begin{array}{l}\text { Hypoglycemia, interference } \\
\text { with cardiac ischemic } \\
\text { preconditioning }\end{array}$ & Withhold on the day of surgery \\
\hline $\begin{array}{l}\text { Meglitinides } \\
\text { (repaglinide) }\end{array}$ & Stimulates insulin release $\left(T^{1} / 2: I \mathrm{~h}\right)$ & Hypoglycemia & Withhold on the day of surgery \\
\hline $\begin{array}{l}\text { Thiazolidinediones } \\
\text { (pioglitazone) }\end{array}$ & $\begin{array}{l}\text { Modulates carbohydrate and fatty acid } \\
\text { metabolism, reduces insulin resistance } \\
\text { and hepatic gluconeogenesis ( } T 1 / 2: 3-8 \mathrm{~h})\end{array}$ & Fluid retention & $\begin{array}{l}\text { Withhold } 24-48 \mathrm{~h} \text { before } \\
\text { surgery }\end{array}$ \\
\hline $\begin{array}{l}\text { Alpha glucosidase inhibitors } \\
\text { (acarbose, miglitol) }\end{array}$ & Reduces intestinal glucose absorption & None & Withhold during fasting \\
\hline $\begin{array}{l}\text { SGLT-2 inhibitors } \\
\text { (dapagliflozine) }\end{array}$ & Reduces glucose reabsorption in kidney & Reduced plasma volume, DKA & Withhold on the day of surgery \\
\hline $\begin{array}{l}\text { DPP-4 inhibitors } \\
\text { (sitagliptin) }\end{array}$ & $\begin{array}{l}\text { Stimulates insulin release and inhibits } \\
\text { glucagon release (glucose-dependent) }\end{array}$ & Unlikely & Continue \\
\hline $\begin{array}{l}\text { GLP-I agonists } \\
\text { (exenatide, liraglutide) }\end{array}$ & $\begin{array}{l}\text { Stimulates insulin release and inhibits } \\
\text { glucagon release (glucose-dependent) }\end{array}$ & Unlikely & Continue \\
\hline
\end{tabular}

Note: *Does not apply to withdrawn biguanides (eg, phenformin, buformin).

Abbreviations: DKA, diabetic ketoacidosis; h, hours; SGLT-2, sodium-glucose cotransporter 2; DPP-4, dipeptidyl peptidase-4; GLP-I, glucagon-like peptide-I; T1/2, contextsensitive half-time. 
Table 2 Time to onset, peak effect, and total duration of various insulin types

\begin{tabular}{|c|c|c|c|}
\hline Insulin type & Onset & Peak effect & Total duration \\
\hline \multicolumn{4}{|l|}{ Short- and rapid-acting insulin } \\
\hline Regular insulin & $30-60 \mathrm{~min}$ & $2-4$ hours & $6-8$ hours \\
\hline Lispro, aspart, and glulisine & $5-15 \mathrm{~min}$ & $30-90 \mathrm{~min}$ & $4-6$ hours \\
\hline \multicolumn{4}{|c|}{ Intermediate acting or premixed insulin } \\
\hline $\mathrm{NPH}$ & $2-4$ hours & 4-10 hours & $10-16$ hours \\
\hline $\mathrm{NPH} /$ regular $(70 / 30,50 / 50)$ & $30-90 \mathrm{~min}$ & Dual & $10-16$ hours \\
\hline \multicolumn{4}{|l|}{ Long-acting insulin } \\
\hline Lantus $^{\odot}$ and Detemir & $2-4$ hours & None & $20-24$ hours \\
\hline Toujeo $^{\odot}$ and Degludec & $30-90 \mathrm{~min}$ & None & $36-42$ hours \\
\hline
\end{tabular}

Abbreviations: min, minutes; NPH, neutral protamine Hagedorn.

patients on Toujeo $^{\odot}$ or Degludec require a dose reduction of their original dose the night before surgery. ${ }^{11}$ Furthermore, caution should be taken in patients with a history of nocturnal or morning hypoglycemia; also, in these patients, a dose reduction is warranted. Rosenblatt et al showed that administration of $80 \%$ of the evening dose of long-acting insulin, compared to $50 \%$ or $60 \%$ of the evening dose, was a safe and effective strategy without a significant increase in hypoglycemic events. ${ }^{57}$ It stands to reason that short-acting mealtime boluses are omitted during fasting. For patients on neutral protamine Hagedorn insulin, the evening meal dose on the day before surgery may be left unchanged, but the morning dose on the day of surgery should be reduced to $50 \%-75 \%$ of the original dose. ${ }^{11,12}$

Patients using an insulin pump should be instructed to maintain insulin infusion on their usual "sleep" basal rate. ${ }^{12,58}$ After resumption of regular intake, mealtime boluses can be restarted as appropriate.

Although the etiology of DM 1 and 2 is completely different, the recommended perioperative management is usually the same. However, research on DM 1 patients undergoing surgery is sparse, as DM 1 represents only $10 \%$ of the diabetic population. In a retrospective cohort of 209 ambulatory patients with DM, patients with DM 1 presented with higher HbA1c levels and had poor glucose regulation during ambulatory surgery when compared to patients with DM $2 .{ }^{59}$ This suggests that patients with DM 1 are a distinctive group and need a different treatment approach than DM 2. This is partly due to the fact that they rely on an exogenous insulin source for 24 hours per day.

\section{Intraoperative considerations}

Despite the abundance of published protocols, few comparative studies have been done on perioperative glucose regulation during ambulatory surgery. Additionally, as mentioned before, protocol compliance for perioperative diabetes regulation is extremely low. Thus, the intraoperative treatment regimen should be as simple as possible - especially for short ambulatory cases - to improve protocol compliance and a uniform treatment of the ambulatory surgical patient with DM (Table 3).

For insulin-naïve patients, a sliding scale regimen was shown to be a simple and effective regimen for perioperative treatment. ${ }^{60}$ This treatment was effective on the condition that glucose was frequently measured and hyperglycemia was always treated with a bolus of intravenous insulin.

In addition, all guidelines advise managing outpatients on insulin by manipulation of their own insulin regimen and avoiding a variable rate of continuous insulin infusion (VRIII) when possible. ${ }^{11,12}$ For in-hospital patients, it has been shown that a basal-bolus regimen with Lantus $^{\odot}$ once daily and three mealtime boluses provides better glucose control than a sliding scale regimen. ${ }^{18}$ However, transferring patients to a basal-bolus regimen on the day of surgery seems unsuitable for ambulatory practice.

Hemmerling et al showed no difference in perioperative glucose values when patients were treated with a sliding scale regimen compared to a continuous glucose-insulin-potassium infusion. ${ }^{61}$ Thus - awaiting evidence on the optimal intraoperative management of DM in ambulatory surgery - the sliding scale regimen seems to be the most suitable option for patients treated with insulin provided they use their regular dose of long-acting insulin.

Multiple strategies exist for determining the appropriate insulin dose. Firstly, sliding-scale regimens provide prespecified insulin doses for multiple ranges of blood glucose values above a certain threshold (eg, $\left.10 \mathrm{mmol} \mathrm{L}^{-1}\right)$. This method is widely used due to its convenience in use. However, sliding-scale regimens do not take patients' total daily dose of insulin or body weight into account. ${ }^{62}$ Therefore, one can also choose to use the patient's usual correction factor. ${ }^{12,13,63}$ 
When a continuous insulin infusion is warranted (eg, DM 1 patients), a VRIII or glucose-insulin-potassium infusion should be used. ${ }^{64}$ The fear of hypokalemia when administering insulin infusion without potassium during short procedures does not seem to be justified. ${ }^{10}$

Insulin pumps can be continued intraoperatively, especially if the surgical procedure is expected to be of short duration. However, some considerations should be taken into account. ${ }^{65,66} \mathrm{~A}$ preoperative checklist may be used to assess pump functioning, programmed settings, and supplies. The pump infusion set should be placed away from the surgical field. When radiography is being used, the pump should be kept out of range to prevent any possible interference. Potential disconnection of the catheter due to patient movement should be monitored. In order to minimize the risk of hypoglycemia, correctional doses of insulin should be given by separate intravenous injection and blood glucose levels should be measured hourly.

Insulin has long been the sole therapy to treat intraoperative hyperglycemia. Insulin may be administered either intravenously or subcutaneously during surgery, each with its own advantages and disadvantages. Guidelines recommend using subcutaneous insulin in patients undergoing ambulatory surgery. ${ }^{12,67}$ Subcutaneous insulin administration is the most convenient and cost-effective strategy. ${ }^{68,69}$ However, subcutaneous insulin becomes unpredictable during the perioperative period due to the altered perfusion of the subcutaneous tissue. ${ }^{70}$ Therefore, we recommend using intravenous insulin, as this prevents stacking of subcutaneous insulin and has predictable pharmacokinetics.

\section{Blood glucose target range}

According to most guidelines, the optimal blood glucose target range for noncritically ill diabetic inpatients is

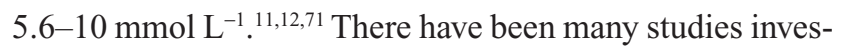
tigating optimal perioperative glycemic targets in major surgery. Whereas several early interventional studies have shown a beneficial effect of tight intraoperative glycemic control, ${ }^{33,72,73}$ most recent studies do not support these findings. ${ }^{74-77}$ In a recent meta-analysis of six studies, ${ }^{75}$ a moderate glycemic target (between 5.6 and $8.3 \mathrm{mmol} \mathrm{L}^{-1}$ ) was found to be most beneficial in terms of postoperative complications and mortality as lower targets (less than $5.6 \mathrm{mmol} \mathrm{L}^{-1}$ ) did not lead to improved outcomes. Moreover, hyperglycemia in patients with DM might be less detrimental than hyperglycemia in patients without DM. ${ }^{78}$

Moderate glycemic control (between 5.6 and $8.3 \mathrm{mmol} \mathrm{L}^{-1}$ ) might not be an achievable target during the short period of ambulatory surgery. However, when blood glucose rises above $10 \mathrm{mmol} \mathrm{L}^{-1}$, collagen syntheses and leukocyte function are depressed, thereby increasing the risk for postoperative complications. ${ }^{79}$ Although the ideal target range for surgical outpatients has not been investigated, all guidelines recommend maintaining blood glucose levels below $10 \mathrm{mmol} \mathrm{L}^{-1}$. .16

\section{Perioperative hypoglycemia}

Patients with older age, prior history of hypoglycemia, longer duration of diabetes, and autonomic neuropathy are at an increased risk for perioperative hypoglycemia. ${ }^{80}$ Most conscious patients experience warning signs and symptoms when blood glucose drops below $3.0 \mathrm{mmol} \mathrm{L}{ }^{-1} .{ }^{81}$ The sympathoadrenal response triggered by hypoglycemia causes neurogenic symptoms, including sweating, tremors, palpitations, and paresthesia. ${ }^{82}$ Neuroglycopenic symptoms - that is, those symptoms resulting from glucose deprivation in the brain, such as confusion, weakness, and seizure - will start to arise as the severity of hypoglycemia increases. Ultimately, profound hypoglycemia may lead to brain death or cardiac arrhythmic death. ${ }^{83}$ Patients with poorly controlled or long-standing diabetes may not experience neurogenic symptoms due to autonomic neuropathy; ${ }^{84}$ in

Table 3 Management of insulin regimens

\begin{tabular}{|c|c|c|c|}
\hline Insulin regimen & Day before surgery & Day of surgery & Comments \\
\hline $\begin{array}{l}\text { Long-acting insulin } \\
\text { (long-acting only, basal component } \\
\text { of basal-bolus regimen) }\end{array}$ & No change & No change & $\begin{array}{l}75 \% \text { of evening or morning dose in case } \\
\text { of Degludec } / \text { Toujeo }^{\odot} \text {, nocturnal or morning } \\
\text { hypoglycemia }\end{array}$ \\
\hline $\begin{array}{l}\text { Intermediate-acting or premixed } \\
\text { insulin }\end{array}$ & No change & $50-75 \%$ of morning dose & $\begin{array}{l}\text { In case of premixed insulin, use the } \\
\text { intermediate-acting component only }\end{array}$ \\
\hline Short- and rapid-acting insulin & No change & $\begin{array}{l}\text { Withhold until resumption of } \\
\text { usual intake }\end{array}$ & \\
\hline $\begin{array}{l}\text { Insulin pump } \\
\text { (basal-bolus) }\end{array}$ & No change & $\begin{array}{l}\text { Maintain basal rate (sleep rate) }{ }^{\mathrm{a}} \\
\text { until resumption of usual intake }\end{array}$ & $\begin{array}{l}\text { Give correctional insulin boluses via } \\
\text { separate injection }\end{array}$ \\
\hline
\end{tabular}

Note: aSafety measures mentioned in this article should be taken into account when using insulin pumps during surgery. 
these patients, only neuroglycopenic symptoms are seen. Poor long-term glycemic control can reduce the threshold for hypoglycemic symptoms causing patients to experience symptoms at blood glucose levels that are otherwise considered normal. ${ }^{81,82}$ Hypoglycemic symptoms in elderly patients are often nonspecific and less obvious due to diminished autonomic responses ${ }^{85}$ Hypoglycemic symptoms are abolished during general anesthesia and sedation and hypoglycemia can only be detected by adequate glucose monitoring. ${ }^{80}$

In well-controlled diabetic patients, blood glucose levels below 3.9 mmol L-1 should be treated promptly. ${ }^{81}$ This will provide sufficient time to prevent symptoms. Perioperative hypoglycemia may be treated with $80-100 \mathrm{~mL}$ of $20 \%$ glucose if venous access is available. ${ }^{11}$ Otherwise, $1 \mathrm{mg}$ of glucagon may be administered subcutaneously. Blood glucose should be reassessed 15 minutes after treatment. ${ }^{12,13}$

\section{Glucose measurement}

Blood glucose levels should be regularly measured in order to keep glucose levels stable and within target range. More importantly, regular monitoring allows for early detection of hypoglycemia. It is advisable to measure blood glucose upon the patient's arrival at the ambulatory facility, beforeand after surgery, and prior to discharge. Surgery lasting less than 2 hours may not require intraoperative glucose testing. Intraoperative measurements should preferably be performed every hour when using intravenous rapid-acting insulin for treating hyperglycemia, as the peak effect of insulin occurs within 20 minutes (Table 2). Evidently, more frequent monitoring is needed in case of hypoglycemia or considerable fluctuation of blood glucose levels.

Perioperative blood glucose levels are most commonly measured using point-of-care capillary glucose devices, as these are convenient and readily available. The difference between capillary and venous glucose is usually small, provided there are no major physiological derangements. ${ }^{19,86}$ However, practitioners have to keep in mind that the US Food and Drug Administration allows a 15\% error margin in monitors and that point-of-care devices typically overestimate blood glucose levels in the hypoglycemic range. ${ }^{86-88}$ Thus, in the hypoglycemic range, more frequent monitoring and verification with central laboratory tests should be performed. ${ }^{12}$

\section{Dexamethasone administration}

Resuming oral intake and their own antidiabetic regime is of high priority in surgical outpatients. Dexamethasone is commonly used as an antiemetic for the prevention of PONV to facilitate the abovementioned target. ${ }^{89,90}$ Intraoperative administration of a single small dose (ie, a mean dose of $4.2 \mathrm{mg}$ ) of dexamethasone in surgical outpatients with DM has been demonstrated to raise blood glucose levels by $1.5 \mathrm{mmol} \mathrm{L}^{-1} .^{10,91}$ One could argue that as long as glucose levels are adequately monitored and treated, a single dose of $4 \mathrm{mg}$ of dexamethasone may be administered as part of PONV prophylaxis in patients with DM. However, one has to keep in mind that the peak effect of dexamethasone is 12 hours after administration when ambulatory patients are already discharged home. ${ }^{92}$ Therefore, we would suggest using dexamethasone as a final option in the multimodal approach for PONV prophylaxis. Furthermore, it is worth pointing out that $8 \mathrm{mg}$ of dexamethasone is not more effective for the prevention of PONV than $4 \mathrm{mg} .{ }^{12}$

\section{Postoperative considerations}

After surgery, patients should be encouraged to resume their normal caloric intake as soon as possible. Once regular intake is resumed, all discontinued oral antidiabetics can often be safely restarted, provided the patient is not hypoglycemic. However, caution should be taken if morning medications were used later than usual. Also, if resumption of normal intake is delayed, the patient's usual treatment regimen should be postponed. Hypoglycemia warrants prolonged observation, at least until the peak effect of the last insulin dose has passed. Patients should be instructed to self-monitor their blood glucose levels regularly after discharge and carry adequate hypoglycemia treatments (eg, 15-20 g of glucose $)^{40}$ while traveling from the ambulatory facility. Furthermore, they need to be provided with a discharge information letter, including a phone number to contact, if they encounter any problems.

\section{Conclusion}

Diabetes is an important risk factor for postoperative complications. Hence, optimal anesthesiologic management of patients with DM is crucial. One of the key principles is minimal disruption of the surgical outpatient's treatment regimen. Considering the short duration of surgery and current evidence, the pursuit of strict glycemic control in every diabetic patient undergoing minor ambulatory surgery may likely be superfluous. However, much is still to be gained by improving preanesthetic care.

\section{Disclosure}

The authors report no conflicts of interest in this work. 


\section{References}

1. Mendis S. Global Status Report on Noncommunicable Diseases. Geneva: World Health Organiztion; 2014.

2. Federation ID. IDF Diabetes Atlas Update Poster. 6th edn. Brussels: International Diabetes Federation; 2014.

3. Salam R. Perioperative management of diabetes mellitus. J Med Soc. 2014;28(1):4-8.

4. Association AH. Utilization and volume. In: Trends Affecting Hospitals and Health Systems. Chicago, IL: AHA; chapter 3; 2015.

5. Blondet JJ, Beilman GJ. Glycemic control and prevention of perioperative infection. Curr Opin Crit Care. 2007;13(4):421-427.

6. Eshuis WJ, Hermanides J, van Dalen JW, et al. Early postoperative hyperglycemia is associated with postoperative complications after pancreatoduodenectomy. Ann Surg. 2011;253(4):739-744.

7. Frisch A, Chandra P, Smiley D, et al. Prevalence and clinical outcome of hyperglycemia in the perioperative period in noncardiac surgery. Diabetes Care. 2010;33(8):1783-1788.

8. Furnary AP, Gao G, Grunkemeier GL, et al. Continuous insulin infusion reduces mortality in patients with diabetes undergoing coronary artery bypass grafting. J Thorac Cardiovasc Surg. 2003;125(5):1007-1021.

9. Ouattara A, Lecomte P, Le Manach Y, et al. Poor intraoperative blood glucose control is associated with a worsened hospital outcome after cardiac surgery in diabetic patients. Anesthesiology. 2005;103(4): 687-694.

10. Polderman JA, Van Velzen L, Wasmoeth LG, et al. Hyperglycemia and ambulatory surgery. Minerva Anestesiol. 2015;81(9):951-959.

11. Membership of the Working Party, Barker P, Creasey PE, Dhatariya K et al. Peri-operative management of the surgical patient with diabetes 2015: Association of Anaesthetists of Great Britain and Ireland. Anaesthesia. 2015;70(12):1427-1440.

12. Joshi G, Chung F, Vann M, et al. Society for Ambulatory Anesthesia consensus statement on perioperative blood glucose management in diabetic patients undergoing ambulatory surgery. Anesth Analg. 2010;111(6):1378-1387.

13. Vann M. Management of diabetes medications for patients undergoing ambulatory surgery. Anesthesiology Clin. 2014;32(2):329-339.

14. Desborough J. The stress response to trauma and surgery. Br JAnaesth. 2000;85(1):109-117.

15. Subramaniam B, Panzica P, Novack V, et al. Continuous perioperative insulin infusion decreases major cardiovascular events in patients undergoing vascular surgery: a prospective, randomized trial. Anesthesiology. 2009;110(5):970-977.

16. Ponce B, Menendez M, Oladeji L, Soldado F. Diabetes as a risk factor for poorer early postoperative outcomes after shoulder arthroplasty. J Shoulder Elbow Surg. 2014;23(5):671-678.

17. Kwon S, Thompson R, Dellinger P, Yanez D, Farrohki E, Flum D. Importance of perioperative glycemic control in general surgery: a report from the Surgical Care and Outcomes Assessment Program. Ann Surg. 2013;257(1):8-14.

18. Umpierrez GE, Smiley D, Jacobs S, et al. Randomized study of basalbolus insulin therapy in the inpatient management of patients with type 2 diabetes undergoing general surgery (RABBIT 2 surgery). Diabetes Care. 2011;34(2):256-261.

19. Evans C, Lee J, Ruhlman M. Optimal glucose management in the perioperative period. Surg Clin North Am. 2015;95(2):337-354.

20. Rassias AJ, Givan AL, Marrin CA, Whalen K, Pahl J, Yeager MP. Insulin increases neutrophil count and phagocytic capacity after cardiac surgery. Anesth Analg. 2002;94(5):1113-1119.

21. Rassias AJ, Marrin CA, Arruda J, Whalen PK, Beach M, Yeager MP. Insulin infusion improves neutrophil function in diabetic cardiac surgery patients. Anesth Analg. 1999;88(5):1011-1016.

22. Alexandraki K, Piperi C, Kalofoutis C, Singh J, Alaveras A, Kalofoutis A. Inflammatory process in type 2 diabetes: the role of cytokines. Ann NY Acad Sci. 2006;1084:89-117.

23. Hamed S, Brenner B, Roguin A. Nitric oxide: a key factor behind the dysfunctionality of endothelial progenitor cells in diabetes mellitus type-2. Cardiovasc Res. 2011;91(1):9-15.
24. Duncan A. Hyperglycemia and perioperative glucose management. Curr Pharm Des. 2012;18(38):6195-6203.

25. Hermanides J, Huijgen R, Henny CP, et al. Hip surgery sequentially induces stress hyperglycaemia and activates coagulation. Neth $\mathrm{J} \mathrm{Med}$. 2009;67(6):226-229.

26. Bergman SA. Perioperative management of the diabetic patient. Oral Surg Oral Med Oral Pathol Oral Radiol Endod. 2007;103(6): 731-737.

27. Krishnamurti U, Steffes MW. Glycohemoglobin: a primary predictor of the development or reversal of complications of diabetes mellitus. Clin Chem. 2001;47(7):1157-1165.

28. Marshall SM, Barth JH. Standardization of HbA1c measurements: a consensus statement. Ann Clin Biochem. 2000;37 (Pt 1):45-46.

29. Alder VA, Yu DY, Su EN, Cringle SJ. Comparison of hematologic parameters in normal and streptozotocin-induced diabetic rats. Lab Anim Sci. 1992;42(2):170-173.

30. Bakhtiani P, Mansuri O, Yadav A, et al. Impact of hyperbaric oxygen on diabetic ulcers is unaffected by glycemic control. Undersea Hyperb Med. 2015;42(3):183-190.

31. Halkos ME, Lattouf OM, Puskas JD, et al. Elevated preoperative hemoglobin A1c level is associated with reduced long-term survival after coronary artery bypass surgery. Ann Thorac Surg. 2008;86(5): 1431-1437.

32. Halkos ME, Puskas JD, Lattouf OM, et al. Elevated preoperative hemoglobin A1c level is predictive of adverse events after coronary artery bypass surgery. J Thorac Cardiovasc Surg. 2008;136(3):631-640.

33. Lazar HL, Chipkin SR, Fitzgerald CA, Bao Y, Cabral H, Apstein CS. Tight glycemic control in diabetic coronary artery bypass graft patients improves perioperative outcomes and decreases recurrent ischemic events. Circulation. 2004;109(12):1497-1502.

34. O'Sullivan CJ, Hynes N, Mahendran B, et al. Haemoglobin A1c (HbA1C) in non-diabetic and diabetic vascular patients. Is $\mathrm{HbA} 1 \mathrm{C}$ an independent risk factor and predictor of adverse outcome? Eur J Vasc Endovasc Surg. 2006;32(2):188-197.

35. Gustafsson UO, Thorell A, Soop M, Ljungqvist O, Nygren J. Haemoglobin A $1 \mathrm{c}$ as a predictor of postoperative hyperglycaemia and complications after major colorectal surgery. Br J Surg. 2009;96(11):1358-1364.

36. Coan KE, Schlinkert AB, Beck BR, et al. Perioperative management of patients with diabetes undergoing ambulatory elective surgery. J Diabetes Sci Technol. 2013;7(4):983-989.

37. DiNardo M, Donihi A, Forte P, Gieraltowski L, Korytkowski M. Standardized glycemic management and perioperative glycemic outcomes in patients with diabetes mellitus who undergo same-day surgery. Endocr Pract. 2011;17(3):404-411.

38. Song R. Mechanism of metformin: a tale of two sites. Diabetes Care. 2016;39(2):187-189.

39. Salpeter S, Greyber E, Pasternak G, Salpeter E. Risk of fatal and nonfatal lactic acidosis with metformin use in type 2 diabetes mellitus. Cochrane Database Syst Rev. 2010;14(4):CD002967.

40. Association AD. Standards of medical care in diabetes-2015. Diabetes Care. 2015;38(suppl 1):S1-S93.

41. Frassdorf J, De Hert S, Schlack W. Anaesthesia and myocardial ischaemia/reperfusion injury. Br J Anaesth. 2009;103(1):89-98.

42. Meneghini L. Perioperative management of diabetes: translating evidence into practice. Cleve Clin J Med. 2009;76(Suppl 4): S53-59.

43. van de Laar FA. Alpha-glucosidase inhibitors in the early treatment of type 2 diabetes. Vasc Health Risk Manag. 2008;4(6):1189-1195.

44. Berlie H, Hurren KM, Pinelli NR. Glucagon-like peptide-1 receptor agonists as add-on therapy to basal insulin in patients with type 2 diabetes: a systematic review. Diabetes Metab Syndr Obes. 2012;5: $165-174$.

45. Meier JJ, Nauck MA. Glucagon-like peptide 1(GLP-1) in biology and pathology. Diabetes Metab Res Rev. 2005;21(2):91-117.

46. Chen D, Lee S, Peterfreund R. New therapeutic agents for diabetes mellitus: implications for anesthetic management. Anesth Analg. 2009;108(6):1803-1810. 
47. de Heer J, Holst J. Sulfonylurea compounds uncouple the glucose dependence of the insulinotropic effect of glucagon-like peptide 1 . Diabetes. 2007;56(2):438-443.

48. Kawano T, Tanaka K, Chi H, et al. Biophysical and pharmacological properties of glucagon-like peptide-1 in rats under isoflurane anesthesia. Anesth Analg. 2012;115(1):62-69.

49. Mudaliar S, Polidori D, Zambrowicz B, Henry RR. Sodium-glucose cotransporter inhibitors: effects on renal and intestinal glucose transport: from bench to bedside. Diabetes Care. 2015;38(12):2344-2353.

50. Lambers Heerspink HJ, de Zeeuw D, Wie L, Leslie B, List J. Dapagliflozin a glucose-regulating drug with diuretic properties in subjects with type 2 diabetes. Diabetes Obes Metab. 2013;15(9):853-862.

51. Agency EM. Review of Diabetes Medicines Called SGLT2 Inhibitors Started. Risk of Diabetic Ketoacidosis to be Examined. London: European Medicines Agency; 2015.

52. Peters AL, Buschur EO, Buse JB, Cohan P, Diner JC, Hirsch IB Euglycemic diabetic ketoacidosis: A potential complication of treatment with sodium-glucose cotransporter 2 inhibition. Diabetes Care. 2015; 38(9):1687-1693.

53. Vann M. Perioperative management of ambulatory surgical patients with diabetes mellitus. Curr Opin Anaesthesiol. 2009;22(6):718-724.

54. Davis DA, Taylor-Vaisey A. Translating guidelines into practice. A systematic review of theoretic concepts, practical experience and research evidence in the adoption of clinical practice guidelines. CMAJ. 1997;157(4):408-416.

55. Cabana MD, Rand CS, Powe NR, et al. Why don't physicians follow clinical practice guidelines? A framework for improvement. JAMA. 1999;282(15):1458-1465.

56. Francke AL, Smit MC, de Veer AJ, Mistiaen P. Factors influencing the implementation of clinical guidelines for health care professionals: a systematic meta-review. BMC Med Inform Decis Mak. 2008;8:38.

57. Rosenblatt S, Dukatz T, Jahn R, et al. Insulin glargine dosing before next-day surgery: comparing three strategies. J Clin Anesth. 2012;24(8):610-617.

58. Corney S, Dukatz T, Rosenblatt S, et al. Comparison of insulin pump therapy (continuous subcutaneous insulin infusion) to alternative methods for perioperative glycemic management in patients with planned postoperative admissions. J Diabetes Sci Technol. 2012;6(5): 1003-1015.

59. Polderman JAW, Broere L, Preckel B, Hermanides J. Predictors of perioperative hyperglycaemia in patients with diabetes type 1 or 2 undergoing ambulatory surgery. Eur JAnaesthesiol. 2015;32(eSupplement 53).

60. Raucoules-Aime M, Labib Y, Levraut J, Gastaud P, Dolisi C, Grimaud D. Use of i.v. insulin in well-controlled non-insulin-dependent diabetics undergoing major surgery. Br J Anaesth. 1996;76(2):198-202.

61. Hemmerling TM, Schmid MC, Schmidt J, Kern S, Jacobi KE. Comparison of a continuous glucose-insulin-potassium infusion versus intermittent bolus application of insulin on perioperative glucose control and hormone status in insulin-treated type 2 diabetics. J Clin Anesth. 2001;13(4):293-300.

62. Hirsch I. Sliding scale insulin-time to stop sliding. JAMA. 2009; 301(2):213-214.

63. McCall AL. Insulin Therapy and Hypoglycemia. Endocrinol Metab Clin North Am. 2012;41(1):57-87.

64. Nassar AA, Boyle ME, Seifert KM, et al. Insulin pump therapy in patients with diabetes undergoing surgery. Endocr Pract. 2012;18(1): 49-55.

65. Boyle M, Seifert K, Beer K, et al. Guidelines for application of continuous subcutaneous insulin infusion (Insulin pump) therapy in the perioperative period. J Diabetes Sci Technol. 2012;6(1):184-190.

66. Ferrari L. New insulin analogues and insulin delivery devices for the perioperative management of diabetic patients. Curr Opin Anaesthesiol. 2008;21(3):401-405.

67. Dhatariya K, Levy N, Kilvert A, et al. NHS diabetes guideline for the perioperative management of the adult patient with diabetes. Diabet Med. 2012;29(4):420-433.
68. Bullu-Sanchis S, Ortega F, Chabrier G, et al. Efficacy of short term continuous subcutaneous insulin lispro versus continuous intravenous regular insulin in poorly controlled, hospitalized, type 2 diabetic patients. Diabetes Metab. 2006;32(4):350-358.

69. Umpierrez G, Latif K, Stoever J, et al. Efficacy of subcutaneous insulin lispro versus continuous intravenous regular insulin for the treatment of patients with diabetic ketoacidosis. Am J Med. 2004;117(5):291-296.

70. Elbers PW, Ince C. Mechanisms of critical illness-classifying microcirculatory flow abnormalities in distributive shock. Crit Care. 2006;10(4):221.

71. Moghissi E, Korytkowski M, DiNardo M, et al; American Association of Clinical Endocrinologists; American Diabetes Association. American Association of Clinical Endocrinologists and American Diabetes Association consensus statement on inpatient glycemic control. Endocr Pract. 2009;15(4):353-369.

72. Giakoumidakis K, Eltheni R, Patelarou E, et al. Effects of intensive glycemic control on outcomes of cardiac surgery. Heart Lung. 2013; 42(2):146-151.

73. van den Berghe G, Wouters P, Weekers F, et al. Intensive insulin therapy in critically ill patients. $N$ Engl J Med. 2001;345(19):1359-1367.

74. Umpierrez G, Cardona S, Pasquel F, et al. Randomized controlled trial of intensive versus conservative glucose control in patients undergoing coronary artery bypass graft surgery: GLUCO-CABG trial. Diabetes Care. 2015;38(9):1665-1672.

75. Sathya B, Davis R, Taveira T, Whitlatch H, Wu WC. Intensity of peri-operative glycemic control and postoperative outcomes in patients with diabetes: a meta-analysis. Diabetes Res Clin Pract. 2013;102(1):8-15.

76. Gandhi G, Nuttall G, Abel M, et al. Intensive intraoperative insulin therapy versus conventional glucose management during cardiac surgery: a randomized trial. Ann Intern Med. 2007;146(4): 233-243.

77. Bhamidipati C, LaPar D, Stukenborg G, et al. Superiority of moderate control of hyperglycemia to tight control in patients undergoing coronary artery bypass grafting. J Thorac Cardiovasc Surg. 2011; 141(2):543-551.

78. Abdelmalak BB, Knittel J, Abdelmalak JB, et al. Preoperative blood glucose concentrations and postoperative outcomes after elective non-cardiac surgery: an observational study. Br J Anaesth. 2014;112(1):79-88.

79. Stagnaro-Green A. Perioperative glucose control: does it really matter? Mt Sinai J Med. 1991;58(4):299-304.

80. Kalra S, Bajwa SJ, Baruah M, Sehgal V. Hypoglycaemia in anesthesiology practice: diagnostic, preventive, and management strategies. Saudi J Anaesth. 2013;7(4):447-452.

81. Cryer P, Axelrod L, Grossman A, et al. Evaluation and management of adult hypoglycemic disorders: an endocrine society clinical practice guideline. J Clin Endocrinol Metab. 2009;94(3):709-728.

82. Cryer P. Symptoms of hypoglycemia, thresholds for their occurrence, and hypoglycemia unawareness. Endocrinol Metab Clin North Am. 1999;28(3):495-500.

83. Cryer P. Hypoglycemia, functional brain failure, and brain death. J Clin Invest. 2007;117(4):868-870.

84. Vinik A, Maser R, Mitchell B, Freeman R. Diabetic autonomic neuropathy. Diabetes Care. 2003;26(5):1553-1579.

85. Abdelhafiz A, Rodriguez-Manas L, Morley J, Sinclair A. Hypoglycemia in older Ppeople-a less well recognized risk factor for frailty. Aging Dis. 2015;6(2):156-167.

86. Pitkin A, Rice M. Challenges to glycemic measurement in the perioperative and critically ill patient: a review. J Diabetes Sci Technol. 2009;3(6):1270-1281.

87. Rebel A, Rice M, Fahy B. Accuracy of point-of-care glucose measurements. J Diabetes Sci Technol. 2012;6(2):396-411.

88. Teodorczyk M, Nandagopalan S, Maguire P, Stegmann J. System accuracy of blood glucose monitoring devices according to the current and proposed ISO 15197 standards. J Diabetes Sci Technol. 2013;7(3):795-797. 
89. De Oliveira GJ, Almeida M, Benzon H, McCarthy R. Perioperative single dose systemic dexamethasone for postoperative pain: a meta-analysis of randomized controlled trials. Anesthesiology. 2011;115(3):575-588.

90. Murphy G, Szokol J, Greenberg S, et al. Preoperative dexamethasone enhances quality of recovery after laparoscopic cholecystectomy: effect on in-hospital and postdischarge recovery outcomes. Anesthesiology. 2011;114(4):882-890.
91. Nazar CE, Echevarria GC, Lacassie HJ, Flores RA, Munoz HR. [Effects on blood glucose of prophylactic dexamethasone for postoperative nausea and vomiting in diabetics and non-diabetics]. Rev Med Chil. 2011;139(6):755-761.

92. Fauci AS, Dale DC, Balow JE. Glucocorticosteroid therapy: mechanisms of action and clinical considerations. Ann Intern Med. 1976;84(3):304-315.

\section{Publish your work in this journal}

Ambulatory Anesthesia is an international, peer reviewed, open access journal publishing articles that address all aspects of ambulatory anesthesia practice, in particular: anesthetic techniques, sedation and safety practices, pharmacokinetics, preoperative evaluation, analgesia interventions, regulatory and compliance issues, postoperative recovery,

Submit your manuscript here: http://www.dovepress.com/ambulatory-anesthesia-journal

\section{Dovepress}

patient satisfaction, administrative topics, and cost analysis themes. The manuscript management system is completely online and includes a very quick and fair peer review system, which is all easy to use. Visit http://www.dovepress.com/testimonials.php to read real quotes from published authors. 